\title{
Use of Physical Restraints in a Rehabilitation Setting: Findings from a Point Prevalence Survey
}

\section{Claudia Lai*}

Centre for Gerontological Nursing, School of Nursing, The Hong Kong Polytechnic University, Hongkong

*Corresponding author: Claudia Lai, Professor \& Director, Centre for Gerontological Nursing, School of Nursing, The Hong Kong Polytechnic University, Hongkong, Email: claudia.lai@polyu.edu.hk

Received date: Feb 20, 2015, Accepted date: Mar 23, 2015, Published date: Mar 30, 2015

Copyright: ( 2015 Claudia Lai. This is an open-access article distributed under the terms of the Creative Commons Attribution License, which permits unrestricted use, distribution, and reproduction in any medium, provided the original author and source are credited.

\begin{abstract}
A point prevalence survey among 125 patients in two units of a rehabilitation facility showed that the physical restraint rate was $12.8 \%(n=16)$. The survey examined the reason(s) for restraint use, whether its use had been explained, consent obtained and documented, whether the restraint had been appropriately applied and patients monitored during the period when restraint was applied, and whether alternatives had been attempted. Interestingly, six patients were found to have had their restraints removed either before or after the survey. A slightly less restrictive form of restraint, boxing gloves, was used for seven patients instead of limbs holders. Three patients remained restrained. The results of this study revealed that there was room for improvement in practice of restraints, and that measures to reduce the use of restraints were not necessarily very costly. Applying physical restraints is counter-productive to rehabilitative care. Nurses and other health disciplines need to be better informed regarding restraint reduction programs.
\end{abstract}

Keywords: Restraint reduction; Restraint alternatives; Rehabilitation; Nursing

\section{Introduction}

Given the questionable benefits and adverse outcomes of physical restraint use, regulatory agencies, licensing organizations and professional and advocacy groups have been calling for a reduction in restraint use [1]. In clinical practice, the use of physical restraints is often governed by hospital guidelines. Since the Nursing Home Reform Act of 1987, restraint rates in the United States (US) have been declining [2]. The average rate of physical restraint use in nursing homes has fallen from more than $40 \%$ in the 1980 s to a current rate of approximately $10 \%[3]$.

Most studies concerning the extent to which physical restraints are used have focused on long-term care settings. The few studies about their use in hospitals indicate prevalence rates ranging from $3.4 \%$ to $18.5 \%$, with restraints applied more frequently on adults aged 65 or older [4]. To search for reports on the prevalence of physical restraint use in rehabilitation settings, a literature search was conducted. Combining a keyword search using "restrain*”, "rehabilitation" and "prevalence" on Medline (1991-present), CINAHL (1991-present), and the British Nursing Index (1992-present), only 13 articles have been located to date. Upon examination, Gallinagh et al. was the only paper that presented information on the prevalence of physical restraint use in a rehabilitation facility in Northern Ireland, with $68 \%$ of the patients subjected to some form of physical restraint [5]. The results of the search revealed that, there is limited information with regard to physical restraint use in rehabilitation settings. Considering that the purpose of a rehabilitation facility is to promote functional independence, it is intriguing as to why physical restraint was so extensively used in rehabilitation units. The results of the literature search point to the limited knowledge we have as clinicians in this regard.
To examine the effects of an intervention program in reducing physical restraint use, our project team conducted a prospective quasiexperimental clinical trial in rehabilitation settings in Hong Kong. The intervention program consisted of staff education and administrative measures implemented through the work of a Restraint Reduction Committee consisting of multiple disciplines.This paper reports the findings from a point prevalence survey which was a part of this clinical trial.

\section{Adverse Effects of Restraint Use}

For the past 20 years, many negative consequences associated with restraint use have been documented, including physical and psychological harm. Evans et al. conducted a systematic review of patient injury and physical restraint devices [6]. The researchers found that physical restraint may increase the risk of death, falls, serious injury and increased duration of hospitalization. Bed rail-related entrapment deaths by asphyxiation as well as bed rail-related falls leading to death have been reported with the use of restraints $[7,8]$. Waist devices pose the same potential risk for death caused by asphyxia as vest restraints [9].

Engberg et al. found that restraint use leads to health decline in patients, including higher walking dependence, poor performance in activities of daily living, and poor cognitive performance [10]. A multitude of physiological changes such as catecholamine rush, breakdown of muscle cells, pulmonary embolism, thrombophlebitis and psychological effects such as nightmares, intrusive thoughts, and avoidance responses have also been observed to result from restraint use [11]. Further, potential negative outcomes include increased incidence of falls, contractures, nosocomial infection, pressure ulcers, psychiatric morbidity, mental health problems, aggressive behavior, and mortality [12].

Mechanical restraint may increase confusion or precipitate regressive behavior and withdrawal [13]. In a study, restraint use 
promoted passivity [14]. Reduced psychological wellbeing has also been observed [15]. Sullivan-Marx (1995) found withdrawal, regression and denial to be adverse responses to routine restraint use in older adults [16]. Engberg et al. (2008) discovered mental health problems such as social isolation and lower cognitive performance in physically restrained nursing home residents [10]. The residents' restraint experience was associated with traumatic emotional reactions such as rage even years later [11].

Despite a general increase in awareness of the harmful effects of enforced immobility as a result of the use of restraints, studies on the attitude of nurses in Hong Kong on this issue have shown that they are reluctant to change their practice. Staff claims that they have already done their best [17], and that they use restraints because of shortage of manpower [18], and that few alternatives are available [19].

\section{Issues of Ethics and Autonomy in Restraint Use}

Autonomy is central to client-centered rehabilitation since it is a pre-requisite for effective participation [20]. Respect for autonomy is based on the right to privacy and self-determination [21]. By definition, restraints are incompatible with the principle of autonomy simply because the procedure involves restricting a patient or limiting their freedom against their will.

\section{Restraint Use in Hong Kong}

The use of physical restraints in healthcare settings is governed by an operational guideline of the Hospital Authority of Hong Kong [22]. The guideline states that the use of restraints should be the last resort, and that the least restrictive alternatives should be used if restraint is deemed necessary. In fact, according to local hospital policy, only a physician can order the use of restraints. Nurses ask physicians to prescribe the order when they deem it necessary to use restraints. Even though evidence shows that restraints are detrimental to health outcomes, nurses still resort to the use of restraints for various purposes. Nurses frequently cite protecting patients from injury [18], falls [4], and interference with treatment [23] as the rationale for using restraints.

Restraint rates between $10 \%$ and $62.5 \%$ have been reported in various settings in Hong Kong [24]. The restraint use in one private nursing home was found to be $18 \%$ [25], while a survey of 14 longterm care facilities revealed that $62.5 \%$ of the residents were restrained using bedside rails [26]. Reportedly, $10 \%$ of the patients in an acute and psycho-geriatric ward were restrained [27]. A recent survey on the attitude of nursing staff towards restraint use in demented patients showed that $75 \%$ of the staff had used different degrees of physical restraint in the previous three months in one public hospital [28].

To investigate the effect of a restraint reduction program on rates of restraint use in rehabilitation facilities, a prospective quasiexperimental trial was conducted. A restraint reduction program was implemented, the key features of which were staff education and administrative support in the form of a multidisciplinary restraint review committee (RRC). One aim of the clinical trial was to examine whether the staff showed any differences in knowledge, attitude, and practices in the use of restraints after the intervention. The staff were surveyed using Janelli et al. questionnaire as validated by Suen et al. $[29,30]$. The members of the research team observed differences in the behavior of the staff on the unit, but were intrigued to discover that when the results of pre- and post-intervention questionnaires were compared, no significant differences were found. The team therefore decided to conduct a point prevalence survey to examine the actual situation in the unit. The finding of this study was reported in [31].

\section{Methods}

\section{Background to the Study Area}

The settings were two medical and geriatric wards (units) of a rehabilitation division in a general hospital in Hong Kong, with a capacity of 128 beds. Patients admitted to the units had mostly been referred by their own general hospital. This study adopted the common definition of restraints, namely "any manual method or physical or mechanical device, material, or equipment attached or adjacent to the individual's body that the individual cannot remove easily which restricts freedom of movement or normal access to one's body" [32].

\section{Data Collection Tools}

The questionnaire used to survey practices on the use of restraints was developed by the research team using the facility's restraint use protocols and drawing on local and international literature on the subject. Data collected by the research assistant included the reason(s) for using restraints, whether the necessity of using a restraint had been explained to the patient and/or the family, whether consent had been obtained, whether the restraint had been applied in an appropriate manner, whether its use had been documented, the types of restraining device used, whether patients had been monitored for well being when the restraint was applied, whether any alternatives had been attempted, and any reports on the behavior of the patients when restraint was applied.

\section{Sampling and Procedures}

All patients on the units were considered eligible participants because the nature of the study was to investigate the point prevalence of restraint of the study site. The decision to conduct a point prevalence of the use of restraints on the unit was known only to members of the research team. The actual date of the survey was chosen by convenience and known to only two members of the team the research assistant (RA) and the senior medical officer in charge of the units. On the day of the survey, the RA arrived at 9 am to collect data. Because the RA had already been appearing in the unit for a long while to collect data, the staff were already desensitized to his presence. It took about an hour to finish collecting the data from each of the units. The time of day for data collection was the same for both units.

\section{Data Analysis and Management}

Point prevalence was calculated using the formula: Prevalence $=$ Number of existing cases on a specific date $\div$ Number of people in the population on this date. After information on the units' restraint rates was obtained, the Senior Medical Officer in-charge led the multidisciplinary team (team) including the disciplines of physical therapy, occupational therapy, nursing and social work on a ward round to discuss whether the use of restraints on each of the restrained patients was appropriate and in line with the hospital's policy. When there were differences of opinion, the team deliberated until they reached a consensus. Descriptive statistics were used when analyzing the data. 
Page 3 of 7

\section{Ethics}

Ethics approval for the project was obtained from the University's Human Subjects Ethics Application Review Committee. Informed or proxy consent was obtained from the participants of this study.

\section{Results}

The total number of participants admitted in the two units was 125 , and restraints were found to have been applied on 16 participants. The point prevalence rate of restraint use on the admitted participants was $12.8 \%$. The mean age of this restrained group was 82.9 (Standard deviation $[\mathrm{SD}]=11.3$ ). Thirty-one percent of the participants were male and $68.8 \%$ were female. The mean Barthel Index upon admission was 13.7 ( $S D=25.6$, range of scores 0-100). Fifty-six percent of the participants suffered from or had a history of stroke, and $37.5 \%$ had been diagnosed with dementia. It was found that all of the restraints had been initiated by the nursing staff. When comparing with the sample profile of the main study, which applied were a mean age of 75.4 (SD10.7), this restrained group was older. The main study sample had a higher percentage of male participants (46.5\%). The mean Barthel Index of the main study group was 12.7 (SD 5.5), only one point lower than that of the restrained group in this survey. Fewer participants in the main study had a history of stroke $(33.8 \%)$, and only $4.6 \%$ of them had dementia - much lower than the restrained group in this point prevalence survey.

The study observed that only two types of restraint were used wrist ties (either side or both wrists) $(n=12,75 \%)$ and vest restraints $(n=4,25 \%)$. Only one type had been used on $69 \%$ of the sample $(\mathrm{n}=11)$, and both types had been applied to 5 participants $(31 \%)$. More than half of the participants $(n=9,56.3 \%)$ had been restrained to prevent interruptions to their treatment (e.g., nasal-gastric feeding tubes), falls (for those who were unsteady or restless) ( $n=4,25 \%)$, and self-injury (scratching of own skin) $(n=2,12.5 \%)$. Restraints were used on one participant $(6.3 \%)$ to maintain hygiene (the participant kept pulling on his soiled briefs). Because the time of the day was morning, the restrained participants were either sitting up in bed or in a chair.

With regard to the methods for applying restraints, allthe participants had restraints whether were of an appropriate size applied. The team determined that there was enough padding for all of those who needed it (e.g., extra padding for wrist ties). However, only 12 participants (75\%) were restrained using the right level of tightness, with the remainder being restrained too tightly. Half had their activities of daily living needs attended to (e.g., toileting needs), as documented in the case notes or reported by the participant.

There was documentation on the initiation and maintenance of restraints for $n=13(81.3 \%)$ of the restrained cases recorded in the participant's case notes and information on the types of restraints that had been applied, the time of application, the participant's condition and responses while being restrained, whether the participant had been continuously monitored during the period of restraint, and the time of removal (for restraints that were applied intermittently). Nine participants $(56.3 \%)$ had regular reviews of the need to restrain documented in their charts, and the use of alternatives was documented for four participants (25\%). However, for none was there any documentation on whether the participant and/or the family had been informed about the use of restraints or whether their consent had been obtained. The hospital's policy is that families must be informed when a decision to use restraints has been made, but the policy had apparently not been followed (Table 1).

\begin{tabular}{|c|c|c|}
\hline & $\mathrm{n}$ & Mean (range) $\pm S D$ \\
\hline Age & 16 & $82.9(62-97) \pm 11.3$ \\
\hline Barthel Index (range 0-100) & 15 & $13.7(0-97) \pm 25.6$ \\
\hline Length of Stay (days) & 16 & $60.9(14-189) \pm 45.6$ \\
\hline \multirow[t]{2}{*}{ Number of Medical Diagnoses } & 16 & $3.0(1-5) \pm 1.2$ \\
\hline & $\mathrm{n}$ & $\%$ \\
\hline Gender & 5 & 31.3 \\
\hline Female & 11 & 68.8 \\
\hline \multicolumn{3}{|l|}{ Male } \\
\hline \multicolumn{3}{|l|}{ Mental Status } \\
\hline Orientated & 3 & 18.8 \\
\hline Disorientated / confused & 4 & 25 \\
\hline Difficulty in communication & 2 & 12.5 \\
\hline Drowsy & 7 & 43.8 \\
\hline \multicolumn{3}{|l|}{ Functional } \\
\hline Mobile but needing supervision & 1 & 6.3 \\
\hline Needing assistance in walking & 3 & 18.8 \\
\hline Chair-bound / bed-bound & 12 & 75 \\
\hline \multicolumn{3}{|l|}{ Diagnosis } \\
\hline Cerebral vascular accident & 9 & 56.3 \\
\hline Dementia & 6 & 37.5 \\
\hline Hypertension & 5 & 31.3 \\
\hline Lower limb fracture & 5 & 31.3 \\
\hline Congested heart failure & 4 & 25 \\
\hline Pneumonia & 4 & 25 \\
\hline Ischemic heart disease & 3 & 18.8 \\
\hline Epilepsy & 2 & 12.5 \\
\hline Atrial fibrillation & 2 & 12.5 \\
\hline Gastrointestinal bleeding & 1 & 6.3 \\
\hline Bronchitis & 1 & 6.3 \\
\hline Anemia & 1 & 6.3 \\
\hline Asthma & 1 & 6.3 \\
\hline Chronic renal failure & 1 & 6.3 \\
\hline Myocardial infarction & 1 & 6.3 \\
\hline Hernia & 1 & 6.3 \\
\hline
\end{tabular}


Page 4 of 7

\begin{tabular}{|l|l|l|}
\hline Diabetes mellitus & 1 & 6.3 \\
\hline
\end{tabular}

Table 1: Demographic and clinical characteristics of participants $(\mathrm{N}=16)$

The decisions made by the team on the use of restraints included removing all restraints for three participants (18.8\%), and replacing wrist ties with "boxing gloves" (made of tube bandages stuffed with cotton) for seven participants (43.8\%). Interestingly, three participants (18.8\%) found with restrained during the data collection period for establishing point prevalence were discovered to have had their restraints already removed during the ward rounds. Only three participants (18.8\%) remained restrained after the ward rounds.

Among the three participants who had their restraints removed during the ward rounds, one had been admitted to hospital for pneumonia and was using nasal oxygen. The recommendation was to try to wean the participant off oxygen. The nasal cannula was therefore removed, leaving no need for a wrist tie to be used. Another participant had been admitted due to dizziness and diagnosed of a cerebral vascular accident (CVA). He had a history of falls, from which he had fractured a femur, leading to an operation. He was oriented, capable of following instructions, and able to walk unaided under supervision. The team decided that his bed could be moved closer to the nurses' station for observation, and that there was no need for a vest restraint. The last participant was admitted due to sudden weakness and was diagnosed of CVA. She was restless and disoriented. Diversion of activities were recommended and her vest restraint was removed.

Alternatives to restraints were defined in this study as the means employed to reduce the restrictiveness of the restraints use, not necessarily their removal. Alternatives were identified for ten participants $(62.5 \%)$. Out of the three who remained restrained, one had herpes zoster, and wrist ties had been applied on both arms to prevent her from scratching her skin. The team decided that further medical investigation and treatment would be required before alternatives to restraints would be considered. The second participant was an older woman with dementia, who had been admitted because of a stroke andbilateral wrist ties were applied to stop her from pulling out her nasogastric feeding tube. The team did not discuss her case in detail, as she was about to be discharged. The third case was a male participant with dementia and a history of CVA. According to the staff, a vest restraint was applied to him because of his confusion and restlessness. The team decided to consult a psychiatrist for this participant (Table 2).

\begin{tabular}{|l|l|l|}
\hline & $\mathrm{n}$ & $\%$ \\
\hline Types of Restraint Used & & \\
\hline Limb holder & 12 & 75 \\
\hline Vest & 4 & 25 \\
\hline & & \\
\hline Number of Types of Restraint Used & & \\
\hline 1 & 11 & 68.8 \\
\hline 2 & 5 & 31.3 \\
\hline & & \\
\hline
\end{tabular}

\begin{tabular}{|c|c|c|}
\hline \multicolumn{3}{|l|}{ Application of Restraint } \\
\hline Appropriate size & 16 & 100 \\
\hline Enough padding & $15^{\mathrm{ii}}$ & 100 \\
\hline Appropriate securing method & 15 & 93.8 \\
\hline Appropriate tightness & 12 & 75 \\
\hline Appropriate site & 10 & 62.5 \\
\hline \multicolumn{3}{|l|}{ Documentation ii } \\
\hline Reasons & 13 & 81.3 \\
\hline Restraint types & 13 & 81.3 \\
\hline Time of application & 13 & 81.3 \\
\hline Patient's behavior during restraint & 13 & 81.3 \\
\hline Continuous monitoring & 13 & 81.3 \\
\hline $\begin{array}{l}\text { Time of removal (e.g., intermittent } \\
\text { use) }\end{array}$ & $6^{\mathrm{iii}}$ & 75 \\
\hline Regular review of need to restrain & 9 & 56.3 \\
\hline Alternatives tried & 4 & 25 \\
\hline Consent / family informed & 0 & 0 \\
\hline \multicolumn{3}{|l|}{$\begin{array}{l}\text { Staff's Reasons for Applying } \\
\text { Restraints }\end{array}$} \\
\hline Prevention of treatment interruption & 9 & 56.3 \\
\hline Prevention of fall & 2 & 12.5 \\
\hline Restlessness & 2 & 12.5 \\
\hline Prevent self-injury & 2 & 12.5 \\
\hline Other (hygiene reasons) & 1 & 6.3 \\
\hline \multicolumn{3}{|l|}{ Decision by Team } \\
\hline $\begin{array}{l}\text { Replaced limb holders by boxing } \\
\text { gloves }\end{array}$ & 7 & 43.8 \\
\hline Remain restrained & 3 & 18.8 \\
\hline Remove restraint & 3 & 18.8 \\
\hline $\begin{array}{l}\text { Restraint removed before team } \\
\text { rounds }\end{array}$ & 3 & 18.8 \\
\hline
\end{tabular}

Table 2: Spread of physical restraint practices and point prevalence survey $(\mathrm{N}=16)$, ${ }^{\mathrm{i}}$ Not applicable in 1 case, ii No documentation of restraint could be found in 3 cases with limb holders, ${ }^{\text {iii }}$ Not applicable in 7 cases

\section{Discussion}

The point prevalence rate of physical restraint use in these rehabilitation facilities in Hong Kong was $12.8 \%$. The rate was close to 
the pre-intervention restraint rate of $11.5 \%$ and the post-intervention restraint rate of $13.6 \%$ (measured over a period of five months) [31]. Similar to the report of Hamers et al. [23], patients with a history of stroke and a diagnosis related to cognitive impairment comprised a large percentage of the restrained patients in our study. Age was often reported to be one of the predictors of physical restraint usage in studies [33]. Locally, Kwok et al. (2006) observed that around 79\% of older adults in his sample were restrained at one time or another during their hospital stay [34]. Our restrained participants were also older in age.

In accordance with local reports [35], the main reasons given by the nursing staff for using restraints were to prevent disruptions of treatment and to prevent patients from falling. In the literature, wrist restraints were the most widely used, followed by vest restraints [36]; our findings were consistent with this. Although restraints cannot be removed indiscriminately, the need for them to be removed must first be identified. The reasons provided by the staff to justify using restraints showed that they should exercise more discretion before deciding to apply them.

The results also revealed that medical and allied health professionals also needed to share the responsibility for reducing restraints usage. As illustrated in the case in which nasal oxygen was prescribed, if oxygen had no longer been needed, the restraints could have been removed sooner, rather than waiting until the team decided to do so during the survey. Restraints could not be removed from seven patients (43.8\%), but it was recommended that their wrist ties be replaced by "boxing gloves" to prevent interruptions to their treatment. "Boxing gloves" are also a form of physical restraint, although less restrictive. These patients probably needed to be examined with regard to the necessity for naso-gastric tubes, and a determination made as to whether alternative means such as training for oral or gastrostomy feeding could be implemented. The use of restraints should certainly be a last resort. Only a limited number of alternatives to restraints were identified with the team. The US Joint Commission on Accreditation of Healthcare Organizations advocated that restraint alternatives, such as wheelchair adaptations, wedge seats, assisted ambulation and individualized care programs, be considered prior to restraint initiation [37]. For those who need to use wheelchairs, other sources of restraint alternatives such as lap boards and seat belts can provide safe and adequate seating and mobility [38].

Even though there have been initiatives to raise awareness of patient autonomy among healthcare providers, the use of physical restraints on frail or confused older patients continues to be a common practice in many healthcare settings [39] and in many countries [14]. Healthcare workers need to be aware of the tension between the principles of beneficence and non-maleficence [40]. The aim of rehabilitation is to maximize existing strengths and prevent further loss of abilities [41]. This should be a mutual goal, and health professionals need to emphasize the patient's role and provide opportunities for full participation in order for the patient to actualize his/her potential [42]. Restraint use restricts the active participation of patients, which is a crucial component in optimizing recovery [43].

One common theme in the literature is the involvement of the nursing staff as key players in endeavors to reduce restraints used. Similarly Johnson, Ostaszkiewicz, and O'Connell, 2009 reported that the nurses initiated the use of restraints in all cases [44]. Moore and Haralambous indicated that restraints were sometimes applied for the convenience of nursing staff rather than for the safety of patients [19]. Our results indirectly corroborated this possibility. Although, not all types of restraints were found in this study, the two that were used (wrist ties and vest restraints) were highly restrictive, and "boxing gloves" were much better. Less restrictive restraints were identified for the majority of the patients during the ward round, and nearly onefifth had their restraints removed after the ward round. Ackerley et al. demonstrated that there is a strong relationship between quality of life and participation (defined as mobility, independence, and so on [p. 908]) in outpatient rehabilitation over time [45]. Physical restraints greatly hinder a person's ability to engage in life situations and are counter-productive to rehabilitation [46].

This is small-scale study conducted in one rehabilitation setting in Hong Kong. The small sample size is a limitation and replication studies with larger sample sizes would be more informative about the phenomenon of physical restraint use in rehabilitative care. In addition, observational methods may offer better insight as to why and how restraints are applied, thus helping researchers to understand how to eliminate or reduce restraint use in practice.

\section{Conclusion}

Physical restraints should not be considered as an intervention to promote safety in rehabilitation settings, because they are also very likely to cause acute functional decline and many other untoward effects. Physical restraint use also runs counter to the basic principles of rehabilitation. Individual autonomy can easily be sacrificed in the name of patient safety, often without a sound scientific basis or an exploration of the underlying problems or of less restrictive alternatives. The findings of this study in Hong Kong shows that it is possible to identify alternatives without a substantial investment of resources. Nurses need to reflect on how restraints are actually being used and take steps to bring about changes in practice.

\section{Recommendations}

Although nurses are aware of the ethical dilemmas arising from the use of physical restraints and are uncomfortable with their decision to use them, they often feel that they have no alternatives if they are to keep the patient safe [47], or that it is easier to apply restraints than think of alternatives [19]. Nurses would benefit from exposure to technologies that could improve patient and caregiver safety [48]. The hospital should provide more training and resources to encourage staff to reduce restraint use. The hospital also needs to better document any attempts to use restraints. Ongoing patient assessments must be in place to support any continued use of restraints. The observation that, there was no documentation on whether consent had been obtained was particularly alarming.

If hospital administrations are serious about reducing the prevalence of restraint use, they should get nurses actively involved in such initiatives. To ensure patient safety, care alternatives need to be realized, as not all restraints can be removed. Restraint reduction is not welcomed by every health facility out of concern that removing restraints will increase the cost of care, as more staff might be required to look after patients or residents. Many of the alternatives identified during the ward round in this study were simple strategies, inexpensive and easy to carry out. Perseverance and a commitment to changing current practices are the keys to success in reducing restraint use. 


\section{References}

1. Barton SA, Johnson MR, Price LV (2009) Achieving restraint-free on an inpatient behavioral health unit. J Psychosoc Nurs Ment Health Serv 47: 34-40.

2. Centers for Medicare \& Medicaid Services (2008) Freedom from unnecessary physical restraints: Two decades of national progress in nursing home care. Department of Health and Human Services, US.

3. Castle NG, Engberg J (2009) The health consequences of using physical restraints in nursing homes. Med Care 47: 1164-1173.

4. Minnick AF, Mion LC, Johnson ME, Catrambone C, Leipzig R (2007) Prevalence and variation of physical restraint use in acute care settings in the US. J Nurs Scholarsh 39: 30-37.

5. Gallinagh R, Nevin R, McIlroy D, Mitchell F, Campbell L, et al. (2002) The use of physical restraints as a safety measure in the care of older people in four rehabilitation wards: findings from an exploratory study. Int J Nurs Stud 39: 147-156.

6. Evans D, Wood J, Lambert L (2003) Patient injury and physical restraint devices: a systematic review. J AdvNurs 41: 274-282.

7. Joint Commission on Accreditation of Healthcare Organizations, Sentinel Event Statistics Update. (2002) Bed rail-related entrapment deaths. Retrieved May 19, 2011 from http://www.jointcommission.org/ sentinel_event_alert_issue_27_bed_rail-related_entrapment_deaths/

8. Nowicki T, Fulbrook P, Burns C (2010) Bed safety off the rails. Aust Nurs J 18: 31-34.

9. Capezuti E, Brush BL, Won RM, Wagner LM, Lawson WT (2008) Least restrictive or least understood? Waist restraints, provider practices, and risk of harm. J Aging Soc Policy 20: 305-322.

10. Engberg J, Castle NG, McCaffrey D (2008) Physical restraint initiation in nursing homes and subsequent resident health. Gerontologist 48: 442-452.

11. Mohr WK1, Petti TA, Mohr BD (2003) Adverse effects associated with physical restraint. Can J Psychiatry 48: 330-337.

12. Feng Z, Hirdes JP, Smith TF, Finne-Soveri H, Chi I, et al. (2009) Use of physical restraints and antipsychotic medications in nursing homes: a cross-national study. Int J Geriatr Psychiatry 24: 1110-1118.

13. Evans LK, Strumpf NE (1990) Myths about elder restraint. Image J NursSch 22: 124-128.

14. Saarnio R, Isola A (2009) Use of physical restraint in institutional elderly care in Finland: perspectives of patients and their family members. Res GerontolNurs 2: 276-286.

15. Haut A, Köpke S, Gerlach A, Mühlhauser I, Haastert B, et al. (2009) Evaluation of an evidence-based guidance on the reduction of physica restraints in nursing homes: a cluster-randomised controlled trial [ISRCTN34974819]. BMC Geriatr 9: 42.

16. Sullivan-Marx EM (1995) Psychological responses to physical restraint use in older adults. J Psychosoc Nurs Ment Health Serv 33: 20-25.

17. Lai CKY, Wong IYC (2004) Creating a stronger foundation for practice change through changing cultures, not just providing education. Paper presented at the Second World Congress on Long Term Care in Chinese Communities, Taiwan, October 28-30, 2004, p.85-88.

18. Lane C, Harrington A (2011) The factors that influence nurses' use of physical restraint: A thematic literature review. Int J NursPract 17(2): 195-204.

19. Moore K, Haralambous B (2007) Barriers to reducing the use of restraints in residential elder care facilities. J Adv Nurs 58: 532-540.

20. Cardol M, De Jong BA, Ward CD (2002) On autonomy and participation in rehabilitation. Disabil Rehabil 24: 970-974.

21. Mohr WK (2010) Restraints and the code of ethics: An uneasy fit. Arch Psychiatr Nurs 24: 3-14.

22. Hospital Authority Head Office (HAHO) Guideline (2005) Clinical guidelines on the use of physical restraints in adult setting. Hong Kong: Hospital Authority of Hong Kong.

23. Hamers JP, Gulpers MJ, Strik W (2004) Use of physical restraints with cognitively impaired nursing home residents. J Adv Nurs 45: 246-251.
24. Chinese University of Hong Kong (CUHK) (2006) Experience in and attitude towards the use of restraints on demented patients among the nursing staff survey results. CUHK, Faculty of Public Health cum the Nethersole School of Nursing Press Release: Hong Kong, China.

25. Lai CKY, Kong SKF, Chow SKY, Lee JJCS, Lok CKW (2003) A study on a restraint reduction program in a local nursing home. Asian Journal of Nursing Studies 6(2): 1-10.

26. Woo J, Hui E, Chan F, Chi I, Sham A (2004) Use of restraints in longterm residential care facilities in Hong Kong SAR, China: predisposing factors and comparison with other countries. J Gerontol A Biol Sci Med Sci 59: M921.

27. Chien WT (1999) The use of physical restraints to psychogeriatric patients in Hong Kong. Issues Ment Health Nurs 20: 571-586.

28. Chinese University of Hong Kong (CUHK) (2006) Experience in and attitude towards the use of restraints on demented patients among the nursing staff survey results. CUHK, Faculty of Public Health cum the Nethersole School of Nursing: Hong Kong, China.

29. Janelli LM, Scherer YK, Kanski GW, Neary MA (1991) What nursing staff members really know about physical restraints. RehabilNurs 16: 345-348.

30. Suen LK, Lai CK, Wong TK, Chow SK, Kong SK, et al. (2006) Use of physical restraints in rehabilitation settings: staff knowledge, attitudes and predictors. J AdvNurs 55: 20-28.

31. Lai CKY, Chow SKY, Suen LKP, Wong IYC (2011) The effect of a restraint reduction program on physical restraint rates in rehabilitation settings in Hong Kong. Rehabil Res PractVol 2011, Article ID 284604, 9 pages. Doi: 10.1155/2011/284604

32. Guttman R, Altman RD, Karlan MS (1999) Report of the Council on Scientific Affairs. Use of restraints for patients in nursing homes. Council on Scientific Affairs, American Medical Association. Arch Fam Med 8: 101-105.

33. Feng Z, Hirdes JP, Smith TF, Finne-Soveri H, Chi I, et al. (2009) Use of physical restraints and antipsychotic medications in nursing homes: a cross-national study. Int J Geriatr Psychiatry 24: 1110-1118.

34. Kwok T, Mok F, Chien WT, Tam E (2006) Does access to bed-chair pressure sensors reduce physical restraint use in the rehabilitative care setting? J ClinNurs 15: 581-587.

35. Lee DT, Chan MC, Tam EP, Yeung WS (1999) Use of physical restraints on elderly patients: an exploratory study of the perceptions of nurses in Hong Kong. J AdvNurs 29: 153-159.

36. Whitman GR, Davidson LJ, Sereika SM, Rudy EB (2001) Staffing and pattern of mechanical restraint use across a multiple hospital system. Nurs Res 50: 356-362.

37. Cotter VT (2005) Restraint free care in older adults with dementia. Keio J Med 54: 80-84.

38. Chaves ES, Cooper RA, Collins DM, Karmarkar A, Cooper R (2007) Review of the use of physical restraints and lap belts with wheelchair users. Assist Technol 19: 94-107.

39. Cheung PP, Yam BM (2005) Patient autonomy in physical restraint. J Clin Nurs 14 Suppl 1: 34-40.

40. Robinson L, Hutchings D, Dickinson HO, Corner L, Beyer F, et al. (2007) Effectiveness and acceptability of non-pharmacological interventions to reduce wandering in dementia: a systematic review. Int J Geriatr Psychiatry 22: 9-22.

41. Murphy G, Reid K (2003) Chronic illness, disability and rehabilitation: The nature and role of personal control variables. Aust J Prim Health 9: 18-24.

42. Meier RH 3rd, Purtilo RB (1994) Ethical issues and the patient-provider relationship. Am J Phys Med Rehabil 73: 365-366.

43. Mott S, Poole J, Kenrick M (2005) Physical and chemical restraints in acute care: their potential impact on the rehabilitation of older people. Int J NursPract 11: 95-101.

44. Johnson S, Ostaszkiewicz J, O'Connell B (2009) Moving beyond resistance to restraint minimization: a case study of change management in aged care. Worldviews Evid Based Nurs 6: 210-218. 
Citation: Claudia Lai (2015) Use of Physical Restraints in a Rehabilitation Setting: Findings from a Point Prevalence Survey. J Nurs Care 4: 240. doi:10.4172/2167-1168.1000240

Page 7 of 7

45. Ackerley SJ, Gordon HJ, Elston AF, Crawford LM, McPherson KM (2009) Assessment of quality of life and participation within an outpatient rehabilitation setting. DisabilRehabil 31: 906-913.

46. World Health Organization (2001) International Classification of Functioning, Disability and Health: ICF. Geneva: World Health Organization.
47. Molasiotis A (1995) Use of physical restraints. 2: Alternatives. Br J Nurs 4: 201-202, 219-20.

48. Nelson A, Powell-Cope G, Gavin-Dreschnack D, Quigley P, Bulat T, et al. (2004) Technology to promote safe mobility in the elderly. NursClin North Am 39: 649-671. 